\title{
The Investigation of The Imperative Sentences In The Oral Language of Geliting Community
}

\author{
Novita Fadhillah Makuasong ${ }^{1}$, Novi ${ }^{2}$
}

\author{
English Department \\ Faculty of Social Sciences Education and Humanities, \\ Muhammadiyah Maumere Teachers Training Institute \\ Maumere, NTT \\ wawanlabira@gmail.com
}

\begin{abstract}
Every language has its way of switching a positive sentence to a question form. However, the way each language does this is based on a grammar set. Besides this, in every language of the world, there are polar questions and there are content questions. In polar questions, a yes/no answer is adequate as a response; while content questions require sentential structure as an answer. In this study, the writer describes the polar questions formation and content questions formation in Geliting dialect, a language situated within Sikka speech form, spoken in Maumere, Flores island Southeast island. This study shows that Geliting dialect operates a kind of derivation in its interrogative formation.
\end{abstract}

Keywords: Imperative Sentences, Geliting dialect, Sikka Krowe language 


\section{INTRODUCTION}

Flores is one of the islands in South East Island Province which has many regions along with its countless regional language. The languages in Flores Island are languages belonging to the Austronesia language family. Keraf (2001) emphasized that the Polynesian Malay group which is a derivative of the Austronesian language consists of two groups, namely the West Polynesia Malay group and the Central/Eastern Polynesia Malay group. West Polynesia Malay Group down languages in the Philippines, Malaysia, Vietnam, Malagasy, western Indonesia (Sumatra, Java, Kalimantan, Sulawesi, Bali, Lombok, and western Sumbawa) while middle/eastern Indonesia decreases languages on the islands of Sumba, Flores, Timor, Central and southern Maluku.

Geliting dialect is a language is used by local people in Geliting village, a small village to the east of Sikka regency. The population of the village is originally Wajo tribe and Bugis tribe from southeast Sulawesi who migrated around a century ago along with their cultures and language. After years of living side by side with native people, they started using native local language mixed with their dialect and created a new dialect. This dialect is later on called Geliting dialect since the inhabitants use it in their daily activities.

Stulpinaitė (2016) said that each language has a specific way of putting words together (syntax), forming new words and parts of speech (morphology), rules for pronunciation (phonology), and more. $\mathrm{He}$ added, within a given language, there are dialects, which consist of further variations in pronunciation (accent), sentence construction (syntax), and the word used to name things (accent), sentence construction introduces the use of differences in spelling conventions, like English, Bahasa Indonesia and Geliting dialect of Sikka Krowe language.

On the other hand, Mukoroli (2011) stated that humans use language for varied functions; to request, negate, question, or to provide information; to complain, promise, or apologize to other humans. In this case, language follows every human in works and activities in their daily life. By using language, more experiences are known by the language's users, so more chances have to know with many different kinds of culture in the world.

Akrofi-Ansah (2010) stated that three types of clauses; are declarative, imperatives, and interrogatives. Each of these clause types is associated with particular speech acts. Konig and Siemund stated that declarative is used for asserting, claiming, stating, accusing, criticizing, promising, and guaranteeing; imperatives are employed in issuing commands for a certain action to be taken by the addressee. Interrogatives are conventionally associated with the speech act of requesting information. Besides, based on their syntactic and semantic properties, interrogatives are divided into two broad types, namely, polar interrogatives and constituent interrogatives. These two categories of interrogatives are also known in the literature as Yes/No questions and content questions respectively. Yes/No questions or polar questions are so-called because they require just Yes or No for an answer. This does not mean that the answer could not be more than Yes/No, but it suffices to respond with Yes/No as answers for such questions. But on the other hand, content question or $W H$-question requires a sentential answer.

According to Azar (2003) who stated that imperative sentences are used to give commands, 
make a polite request and give directions. It seems that the use of imperative sentences is wide and varied. This sentence is also called the sentence order or request. An imperative sentence is a sentence that aims to give orders to others to do something. In oral form, sentence intonation is characterized by the high command. An imperative sentence is a sentence that is set up to provoke the response in the form of the action. Based on the definition above, the writer concludes briefly those imperatives sentences are sentences that are used by someone to give commands, requests, and directions to other people for doing something.

Here are some illustrations of Yes/No interrogatives in English.

(1) a. Have you taken the book?

b. Will John eat the food?

c. Do the people know that you have gone?

d. Can I buy a car for you?

e. Shall I go with them?

While constituent or content interrogatives demand answers that provide the kind of information indicated by the interrogative word or phrase that is used to ask the question. For example in (2) below, each question requires different information in the answer. For instance, in (2a), location is being enquired, in (2b) personality is the focus, in (2c), time is what is being asked for, in (2d) something of [ \pm animate] in nature is what is being queried while in (2e) it is the manner of doing $x$ that the person asking the question is seeking to know, while in (2f) the reason for doing $x$ is the focus. The questions that are considered above are as follow.

(2) a. Where is the car?
b. Who is coming?
c. When are you going?
d. What is this?
e. How were you beaten?
f. Why were you beaten?

Constituent/content questions are called WHquestions because such questions, in most cases in English, are signaled by $W H$-words such as who, what, where, when, etc. It is from these shortcut symbols that linguists have adopted the nomenclature even though there is no such acronym in the types of question formations in Sikka Krowe language.

This paper studied both the polar and content questions in Geliting dialect of Sikka Krowe language. Like many other languages, both Yes/No and content interrogatives are attested. Each of these question types requires a question marker that signifies that the sentence or utterance is interrogative and that it requires an answer. As far as the writer is concerned, there is no literature about Geliting dialect of Sikka Krowe language.

\section{RESEARCH METHOD}

This research took place in Geliting village of Sikka Regency and focused on the analysis of Geliting dialect in Sikka Krowe interrogative sentences. This study was done through the following steps: collecting the data, analyzing the data, and presenting the result of the data analysis. The data were obtained from 25 adults from Geliting community through interviews, observation, and library research.

The objective of the study is to classify the types of interrogative sentence found Geliting dialect. This research is descriptive qualitative, because of the 
purposes it to find out and classify the types of interrogative sentence found Geliting dialect, Darmawan, (2019) stated that descriptive-qualitative research to examine social phenomena from participant's angles where researchers are key instruments. The current research adopted the fundamental approaches in analyzing the output from the interview. The analysis includes data reduction, transcription of interviews, data display, and the conclusion.

\section{RESUlt AND DISCUSSION}

Historically FINDING

1. Yes/No Questions in Geliting dialect of Sikka language

The markers Yes/No Questions in English imperative sentence marked by an auxiliary verb or do/does and by using a question mark which is placed in the final position of the sentence. The other way is by raising the ends of the word within the sentence. The example is raising the form of the last word of the sentence, the tone is different.

For examples
a. Will you come with me?
b. Does he go to the cinema?
c. Do I have to go with him?

On the other way, there are two ways by which yes/no or polar interrogatives are formed in Geliting dialect of Sikka language. Yes/No Questions in Geliting dialect of Sikka language started by subject and raising the last sound that ends the verb within the sentence. The other way is by marking with $e h, k a$, and $k o$ in the middle of the last of the sentence, and every marker has a different function. Base on some examples above, it can be derived that the interrogative sentence in Geliting dialect of Sikka Krowe language formation is $\mathrm{S}+$ Auxiliary verb + verb + object.

For examples

a. Will you go to the school? ( Au ga'i bano e sikola ko)

$A u$ means You, ga'i means will, and sometimes its function like an auxiliary verb in English, bano means go, sikola means school, and $k a$ is used as a question mark

b. Does he go to the cinema? (Nimu bano $e$ bioskop ko? )

Nimu means him, bano means go, $k a$ is used as a question mark

c. Do I have to go with him? ( A'u bano nora nimu ko? )

$A^{\prime} u$ means I, bano means go, nora means with, nimu means him, and $k a$ is used as a question mark

d. Did you eat this morning? (Au gea kawu he'i $k o$ ? )

$A u$ means you, gea means to eat, kawu means morning, he' $i$ means this, and $k a$ is used as a question mark

e. Have you eaten this morning? (Au gea ba kawu he'i ko? )

$A u$ means you, gea means to eat, kawu means morning, he'I means this, and $k a$ is used as a question mark

f. Should I go to the doctor? ( $A$ 'u naha bano $e$ dokter ko?)

A'u means I, naha means should, bano means go, $k a$ is used as a question mark

g. Would you buy the book? ( $A$ 'u ga'i ko boter buku he'i ) 
Ga' $i$ means will and sometimes its function as an auxiliary verb in English, au means you, boter means buy
[6] Stulpinaitè, M., Horbačauskienè, J., \& Kasperavičienė, R. (2016). Issues in Translation of Linguistic Collocations. Studies About Languages, (29), 31-41.

\section{CONCLUSION}

Based on the analysis that has been done, it can be concluded that the formation of imperative sentences in the Geliting dialect of Sikka Krowe, Kewapante District, Sikka Regency as follows; the imperative sentence is marked by the raising the last sound of the sentence, imperative sentences are marked by $e h, k a$, and $k o$ in the middle of the last of the sentence and every marker has a different function, imperative sentences are marked by $e h$ in the initial sentence

There are still many aspects that can be analyzed about imperative sentences, their types, and the characteristics of each imperative sentence type. Finally, the researcher can analyze aspects of imperative sentences and their types and characteristics in the Geliting dialect, and the results studies can be used as early as possible information to conduct further research.

\section{REFERENCES}

[1] Azhar Arsyad. 2013. Media Pembelajaran. Jakarta: Raja Grafindo Persada.

[2] Akrofi-Ansah, M. 2010. Focused constituent interrogatives in Larteh. Nordic Journal of African Studies, 19.2. 98 - 107.

[3] Darmawan \& Suryoputro, 2019, The Comparison of the Phonological Features of Sikka Language and English, Vol. 4, No. 1, 2019, 64-72 DOI: 10.22236/JER_Vol4Issue 1

[4] Keraf, G. (2001). Komposisi: Sebuah Pengantar Kemahiran Berbahasa, Cetakan XII. Ende: Nusa Indah.

[5] Mukoroli, J. (2011). Effective vocabulary teaching strategies for the English for academic purposes ESL classroom. 